\title{
RESPONSES OF ISOLATED DOG CORONARY ARTERIES TO TYRAMINE
}

\author{
Shigehiro HAYASHI and Noboru TODA* \\ Department of Pharmacology, Shiga University of Medical Sciences. \\ Seta, Ohtsu 520-21. Japan
}

Accepted October 5, 1981

\begin{abstract}
In isolated dog coronary arteries contracted with prostaglandin $F_{2 \infty}$, tyramine in concentrations of $10^{-6}$ and $5 \times 10^{-6} \mathrm{M}$ caused relaxations, but it produced contractions at $2 \times 10^{-5} \mathrm{M}$ or higher. The relaxant response to tyramine was attenuated, but the contractile response was enhanced at the second trial as compared with the responses at the first. Relaxations induced by low concentrations of tyramine were reversed to contractions by treatment with propranolol $\left(10^{-6} \mathrm{M}\right)$ or sotalol $\left(10^{-5} \mathrm{M}\right)$, and were abolished by cocaine $\left(3 \times 10^{-6} \mathrm{M}\right)$ or bretylium $\left(2 \times 10^{-5} \mathrm{M}\right)$. In coronary arteries isolated from reserpine $(0.5 \mathrm{mg} / \mathrm{kg})$-pretreated dogs, tyramine produced only a contraction. Under resting conditions, contractions induced by tyramine $\left(5 \times 10^{-6}\right.$ to $\left.2 \times 10^{-3} \mathrm{M}\right)$ were potentiated by cocaine and propranolol, and were inhibited by phentolamine. Norepinephrine produced a dose-dependent relaxation in the arteries contracted with prostaglandin $\mathrm{F}_{2 \text { s. }}$ In the presence of propranolol, the arteries under resting conditions were contracted by norepinephrine. the contraction being suppressed by treatment with phentolamine. It may be concluded that relaxations of dog coronary arteries induced by tyramine are mediated by liberation of norepinephrine from adrenergic nerves which stimulates betaadrenoceptors in the smooth muscle. It seems likely that the tyramine $\left(2 \times 10^{-5} \mathrm{M}\right.$ or higher)-induced contraction is not mediated by norepinephrine released, but it is partly due to a direct action on alpha-adrenoceptors
\end{abstract}

Tyramine releases norepinephrine from organs and tissues innervated adrenergically. In a variety of arteries isolated from different regions (e.g., aorta (1), ear artery (2). mesenteric artery (3)), tyramine produces a contraction mediated by the release of norepinephrine from adrenergic nerves. whereas the tyramine-induced contraction of dog cerebral arteries is derived mainly from direct alpha-adrenoceptor stimulation (3). Vasodilatation in response to stimulation of adrenergic nerves or to norepinephrine has

\footnotetext{
"To whom all correspondence should be addressed.
}

been demonstrated in rabbit facial vein (4) and sheep and dog coronary artery $(5,6)$. Exogenous norepinephrine preferentially stimulates excitatory alpha-adrenoceptors in large coronary arteries but inhibitory betaadrenoceptors in small arteries (6-9). Dog coronary arteries are adrenergically innervated (10. 11). However, little is known concerning the effect of endogenous norepinephrine on the coronary arterial smooth muscle.

The present study was thus undertaken to determine actions of tyramine on coronary arteries isolated from dogs and to analyze 
the mechanism of action of tyramine. particularly in relation to the release of norepinephrine. Responses of isolated coronary arteries to norepinephrine were also investigated.

\section{MATERIALS AND METHODS}

Mongrel dogs of either sex. weighing 6 to $15 \mathrm{~kg}$. were anesthetized with intraperitoneal injections of $50 \mathrm{mg} / \mathrm{kg}$ of sodium thiopental and were sacrificed by bleeding from common carotid arteries. Thirteen dogs were pretreated 20 to $24 \mathrm{hr}$ before the start of experiments with intramuscular injections of $0.5 \mathrm{mg} / \mathrm{kg}$ reserpine: norepinephrine contents in mesenteric and cerebral arteries are diminished by this pretreatment (12). The heart was removed. The distal portion of circumflex branches of the left coronary artery was isolated: the outside diameter was in a range of 0.7 to $2.0 \mathrm{~mm}$. Coronary arteries used were of intermediate sizes in comparison with small $(0.25$ to $0.5 \mathrm{~mm})$ and large (1.5 to $2.4 \mathrm{~mm}$ ) arteries reported by Zuberbuhler and Bohr (6). These arteries were expected to show both contractile and relaxant responses to endogenous norepinephrine. The arteries were helically cut into strips approximately $20 \mathrm{~mm}$ long. The helical strip was fixed vertically between hooks in a muscle bath containing the nutriert solution which was gassed with a mixture of $95 \% \mathrm{O}_{2}$ and $5 \% \mathrm{CO}_{2}$ and was maintained at $37 \pm 0.5^{\circ} \mathrm{C}$ The hook anchoring the upper end of the strip was connected to the lever of a force displacement transducer (Nihon Kohden Kogyo Co., Tokyo. Japan). The resting tension was adjusted to 1.5 to $2.0 \mathrm{~g}$. which has been reported to be approximately optimal for inducing the maximum con. traction (13). Constituents of the solution were as follows $(\mathrm{mM})$ : $\mathrm{Na}^{+}$162.1, $\mathrm{K}^{+} 5.4$. $\mathrm{Ca}^{++}$2.2. $\mathrm{Mg}^{++}$1.0. $\mathrm{Cl}^{-}$159.0. $\mathrm{HCO}_{3}{ }^{-14.9}$, and dextrose 5.6. The $\mathrm{pH}$ of the solution was 7.2 to 7.3. Osmotic adjustment was not made when $\mathrm{K}^{+}$up to $30 \mathrm{mM}$ was added. Before the start of experiments, preparations were allowed to equilibrate for 90 to $120 \mathrm{~min}$ in the bathing media, during which time the fluids were replaced every 10 to $15 \mathrm{~min}$.

Isometric contractions and relaxations were displayed on an ink-writing oscillograph (Sanei Sokki Co., Tokvo. Japan). Most of the arterial strips were contracted with prostaglandin $F_{2 w}\left(10^{-7}\right.$ to $\left.10^{-6} \mathrm{M}\right)$ before tyramine or norepinephrine was added. Tyramine in low concentrations $\left(10^{-6}\right.$ and $\left.5 \times 10^{-6} \mathrm{M}\right)$ relaxed prostaglandin $F_{2 \alpha^{-}}$ contracted arteries, but in concentrations of $2 \times 10^{-5} \mathrm{M}$ or higher contracted them. At the end of these experiments, papaverime was added in a concentration of $10^{-4} \mathrm{M}$. sufficient to cause the maximum relaxation (14); relaxations or contractions induced by tyramine relative to papaverine-induced relaxations are presented. Contractions induced by tyramine and norepinephrine under resting conditions were compared with those induced by $30 \mathrm{mM} \mathrm{K}$. Preparations had been exposed for $30 \mathrm{~min}$ to blocking agents before the dose-response curve for tyramine or norepinephrine was obtained. Results shown in the text and figures are expressed as mean valuestS.E.M. Statistical analyses were made using the Student's t-test. Drugs used were tyramine hydrochloride, dlnorepinephrine hydrochloride, cocaine hydro chloride, d/-propranolol hydrochloride, sotalol hydrochloride, phentolamine mesylate. pro staglandin Fo (Ono Co., Osaka, Japan). bretylium tosylate, aspirin, atropine sulfate. cinanserin hydrochloride, d-chlorpheniramine maleate, hexamethonium bromide and reserpine (Apoplon. Daiichi Pharmaceltica! Co., Tokyo, Japan)

\section{RESULTS}

Responses of coronary arteries to tyramine: The addition of tyramine in concentrations of $10^{-6}$ and $5 \times 10^{-6} \mathrm{M}$ elicited a dose -dependent 
relaxation in all of the 33 helical strips of dog coronary arteries contracted with prostaglandin $F_{2 a}\left(10^{-7}\right.$ to $\left.10^{-6} \mathrm{M}\right)$ (Fig. 1). Similar relaxation was obtained when the arteries were contracted with serotonin $\left(10^{-9}\right.$ to $\left.2 \times 10^{-8} \mathrm{M}\right)$ or angiotensin $\|\left(5 \times 10^{-10}\right.$ to $\left.5 \times 10^{-9} \mathrm{M}\right)$. Further increases in concentrations of tyramine to $2 \times 10^{-5} \mathrm{M}$ or higher

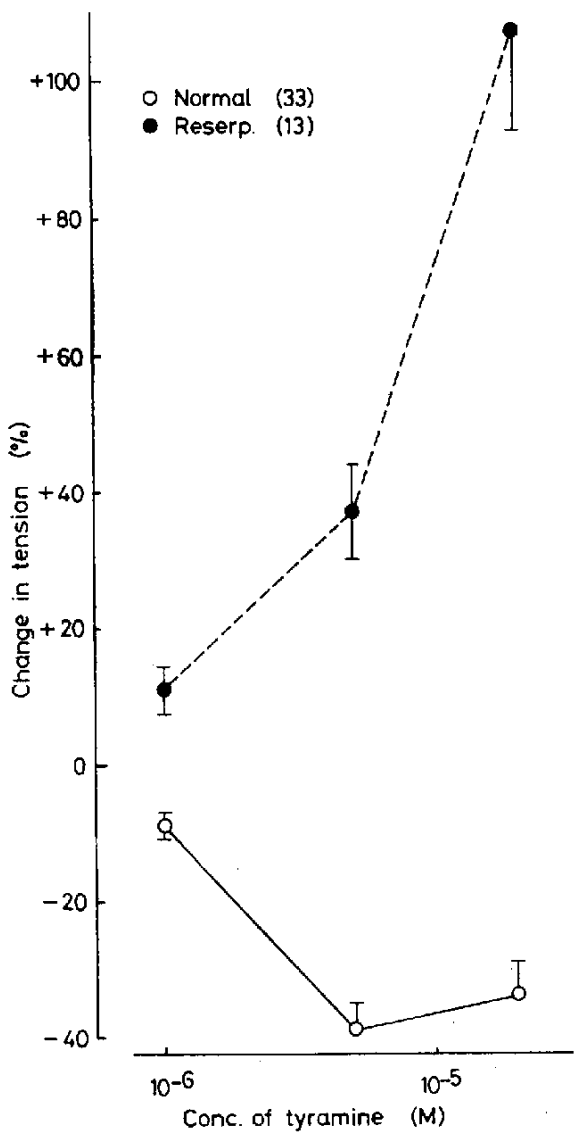

Fig. 1. Dose-response curves of tyramine in coronary arteries isolated from normal and reserpine-pretreated dogs. Preparations were contracted with prostaglandin $F_{2 a}$. Relaxations induced by $10^{-4} \mathrm{M}$ papaverine were taken as $100 \%$; mean absolute values in preparations from normal and reserpine-pretreated dogs were $695 \pm 68 \mathrm{mg}(N=33)$ and $659 \pm 135 \mathrm{mg}$ $(N=13)$. Corresponding values in the control and reserpine-pretreated preparations are significantly different $(P<0.001)$. Figures in parentheses indicate the number of preparations used. Vertical bars represent the S.E.M. contracted these arteries. In coronary arteries isolated from 13 dogs pretreated with reserpine, tyramine $\left(10^{-6} \mathrm{M}\right.$ or higher) did not produce a relaxation but a dosedependent contraction (Fig. 1).

The relaxant response to tyramine of the arteries contracted with prostaglandin $F_{2 \infty}$ was significantly attenuated at the second trial as compared with the response at the first (Fig. 2, left), while the contractile response to tyramine $\left(5 \times 10^{-6}\right.$ to $\left.2 \times 10^{-3} \mathrm{M}\right)$ was significantly enhanced at the 2 nd trial (Fig. 2. right). The dose-response curve of tyramine was reproducible after the 2 nd trials: therefore, the 2 nd dose-response curve was taken as a control in the subsequent experiments with antagonists.

Relaxations induced by tyramine were suppressed by treatment for $30 \mathrm{~min}$ with cocaine $\left(3 \times 10^{-6} \mathrm{M}\right)$ and were reversed to contractions by propranolol $\left(10^{-6} \mathrm{M}\right.$ ) (Fig. $3)$. The relaxant effect was restored following repeated washing of the preparations. Sotalol $\left(10^{-5} \mathrm{M}\right)$ also reversed the tyramine-induced relaxation to a contraction; tyramine $\left(5 \times 10^{-6} \mathrm{M}\right)$ elicited a relaxation of $42: 6 \pm 4.9 \%$ (relative to that induced by $10^{-4} \mathrm{M}$ papaverine) in control media and a contraction of $48.1 \pm 11.6 \%$ $(N=7)$ in the presence of sotalol. Furthermore, breylium $\left(2 \times 10^{-5} \mathrm{M}\right)$ abolished the relaxation $(N=5)$. Treatment with $10^{-7} \mathrm{M}$ phentolamine $(\mathrm{N}=5), 10^{-5} \mathrm{M}$ hexamethonium $(\mathrm{N}=6)$, or $10^{-7} \mathrm{M}$ atropine $(\mathrm{N}=3)$ did not significantly affect the relaxant response to $10^{-6}$ and $5 \times 10^{-6} \mathrm{M}$ tyramine. Under resting conditions, the contractile response to $5 \times 10^{-6}$ $M$ tyramine seen in the arteries treated with $10^{-5} \mathrm{M}$ sotalol was significantly inhibited by $3 \times 10^{-6} \mathrm{M}$ cocaine $(42.0 \pm 5.1 \%$ inhibition, $\mathrm{N}=4)$ and $10^{-7} \mathrm{M}$ phentolamine (68.0 $\pm 7.5 \%$ inhibition, $N=3$ ).

Under resting conditions, the addition of tyramine $\left(2 \times 10^{-5}\right.$ to $\left.2 \times 10^{-3} \mathrm{M}\right)$ produced a dose-dependent contraction in coronary 

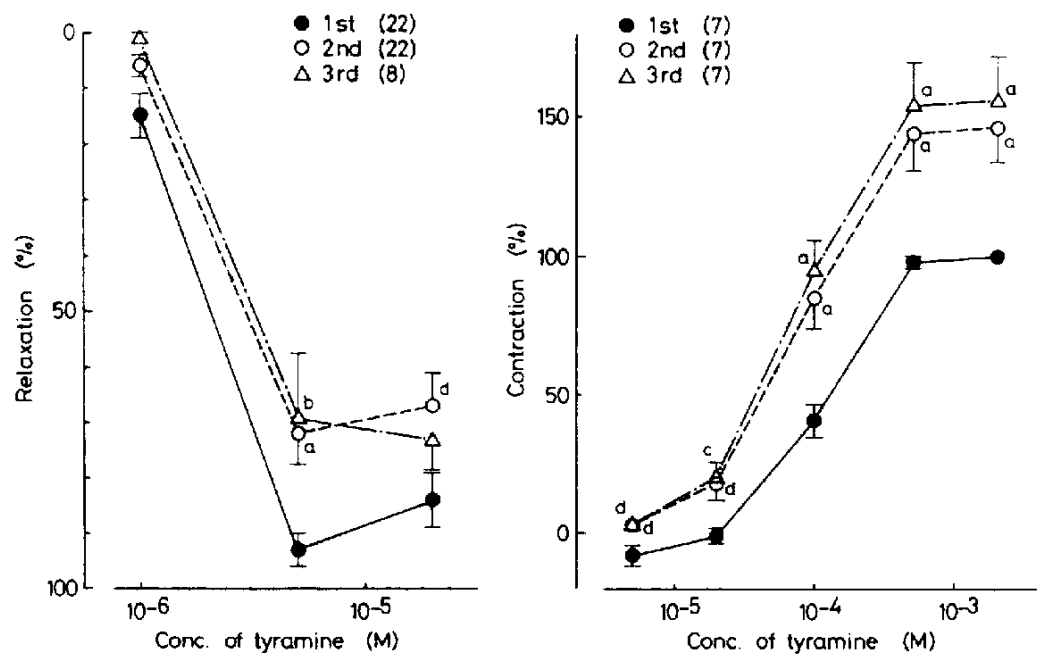

Fig. 2. Dose-response curves of tyramine in coronary arteries obtained during repeated trials of experiments. Preparations were contracted with prostaglandin $F_{2 r}$ in the left figure. Maximum relaxations induced by tyramine at the first trial were taken as $100 \%$; the mean value of the relaxation relative to papaverine $\left(10^{-4} \mathrm{M}\right)$-induced relaxation was $47.7 \pm 4.4 \%$ $(N=22)$. In the right figure, experiments were carried out under resting conditions. Maximum contractions induced by tyramine at the first trial were taken as $100 \%$; the mean value was $707 \pm 177 \mathrm{mg}(N=7)$. a, significantly different from the first trial, $P<0.001$ : b. $P<0.01$ : c, $P<0.02$; d. $P<0.05$.

arterial strips. The mean value of the maximum contractions induced by tyramine relative to those induced by $30 \mathrm{mM} \mathrm{K} \mathrm{K}^{+}$was $46.6 \pm 5.8 \% \quad(N=17)$. Contractile responses to tyramine were significantly potentiated by treatment with propranolol $\left(10^{-6} \mathrm{M}\right)$ and cocaine $\left(3 \times 10^{-6} \mathrm{M}\right)$ (Fig. 4). Contractions induced by tyramine were dose-dependently inhibited by $10^{-7}$ and $10^{-6} \mathrm{M}$ phentolamine (Fig. 5). In the presence of $10^{-6} \mathrm{M}$ propranolol, the contractions were also inhibited by $10^{-6} \mathrm{M}$ phentolamine; inhibitions of the response to $2 \times 10^{-5}$ and $2 \times 10^{-3} \mathrm{M}$ tyramine were $82.2 \pm 3.6$ and $35.6 \pm 5.9 \% \quad(N=5)$. respectively. Cinanserin $\left(10^{-7} \mathrm{M}\right)$, aspirin $\left(5 \times 10^{-5} \mathrm{M}\right)$ and chlorpheniramine $\left(10^{-6} \mathrm{M}\right)$ did not inhibit the tyramine-induced contraction.

Responses of coronary arteries to norepinephrine: The addition of norepinephrine $\left(5 \times 10^{-9}\right.$ to $\left.10^{-5} \mathrm{M}\right)$ caused a dosedependent relaxation when coronary arterial
Strips had been contracted with prostaglandin $F_{2 a}\left(10^{-7}\right.$ to $\left.2 \times 10^{-6} \mathrm{M}\right)$. The maximum relaxation relative to that induced by papaverine $\left(10^{-4} \mathrm{M}\right)$ and the median effective concentration (ED50) of norepinephrine were $92.9 \pm 2.6 \%$ and $[4.0 \pm 0.6] \times 10^{-8} \mathrm{M}(\mathrm{N}=9)$. respectively. In coronary arteries isolated from reserpine-pretreated dogs, the response to norepinephrine was not significantly potentiated: mean values of the maximum relaxation and the ED50 of norepinephrine were $95.1 \pm 1.4 \%$ and $[3.3 \pm 0.8] \times 10^{-8} \mathrm{M}$ $(N=8)$, respectively. The dose-relaxation curve of norepinephrine was not significantly modified by cocaine $\left(3 \times 10^{-6} \mathrm{M}\right)$ and phentolamine $\left(10^{-7} \mathrm{M}\right)$ : mean values of the ED50 of norepinephrine were [6.4 \pm 0.8$]$ $\times 10^{-8} \mathrm{M}(\mathrm{N}=6)$ in control and $[7.8 \pm 1.6]$ $\times 10^{-8} \mathrm{M}$ in the presence of cocaine, and $[5.8 \pm 0.8] \times 10^{-8} \mathrm{M}(\mathrm{N}=6)$ in control and $[4.4 \pm 0.4] \times 10^{-8} \mathrm{M}$ in the presence of phentolamine. Treatment with sotalol $\left(10^{-5}\right.$ 

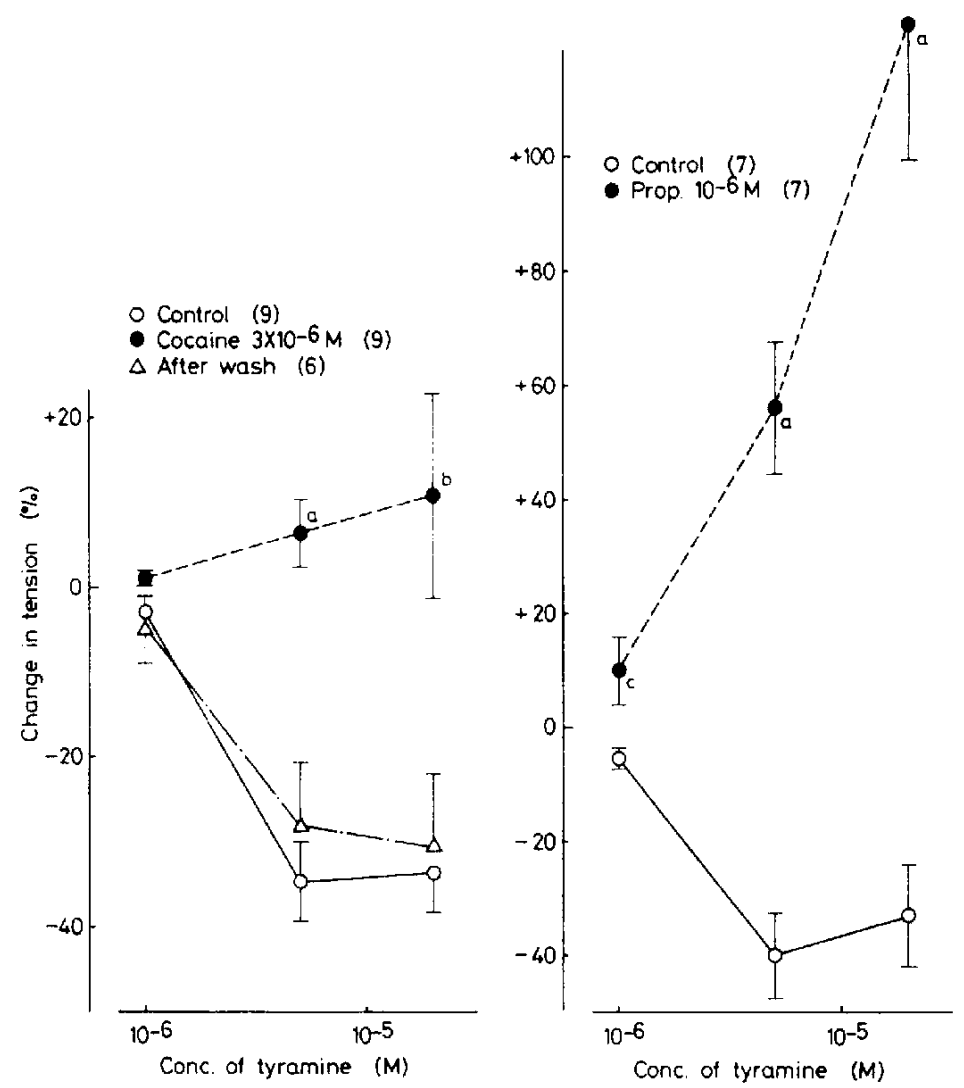

Fig. 3. Modification by cocaine and propranolol of the relaxant response to tyramine in coronary arteries contracted with prostaglandin $F_{2^{a}}$. Relaxations induced by $10^{-4} \mathrm{M}$ papaverine were taken as $100 \%$; mean absolute values for left and right figures were $736 \pm 106 \mathrm{mg}(N=9)$ and $706 \pm 114 \mathrm{mg}(N=7)$, respectively. a. significantly different from controls, $P<0.001 ; b, P<0.01: c, P<0.05$.

M) or propranolol $\left(10^{-6} \mathrm{M}\right)$ reversed the relaxation induced by low concentrations $\left(5 \times 10^{-9}\right.$ to $\left.5 \times 10^{-7} \mathrm{M}\right)$ of norepinephrine to a contraction. and these compounds attenuated the relaxant response to the amine in high concentrations $\left(2 \times 10^{-6}\right.$ to $5 \times 10^{-5} \mathrm{M}$ ).

In the presence of $10^{-6} \mathrm{M}$ propranolol, norepinephrine caused a dose-dependent contraction under a resting condition. The mean value of maximum contractions induced by norepinephrine relative to those induced by $30 \mathrm{mM} \mathrm{K} \mathrm{K}^{+}$was $43.5 \pm 6.4 \% \quad(\mathrm{~N}=13)$. which was less than the maximum contraction induced by tyramine $(63.0 \pm 5.2 \%, N=12)$ in the presence of propranolol. Norepinephrineinduced contraction was attenuated by $10^{-7}$ $\mathrm{M}$ phentolamine and abolished at $10^{-6} \mathrm{M}$ (Fig. 5)

\section{DISCUSSION}

In an earlier report (3), it has been demonstrated that tyramine produces a contraction both in mesenteric and cerebral arteries isolated from dogs; the functional role of endogenous norepinephrine liberated from adrenergic nerves by tyramine is much greater in mesenteric arteries than in cerebral arteries. In contrast, tyramine in concentrations of $10^{-6}$ and $5 \times 10^{-6} \mathrm{M}$ elicited a 
relaxation of dog coronary arteries contracted with prostagiandin $F_{2 x}$. Coronary arteries isolated from reserpine-pretreated dogs failed to relax in response to tyramine. Tachy-
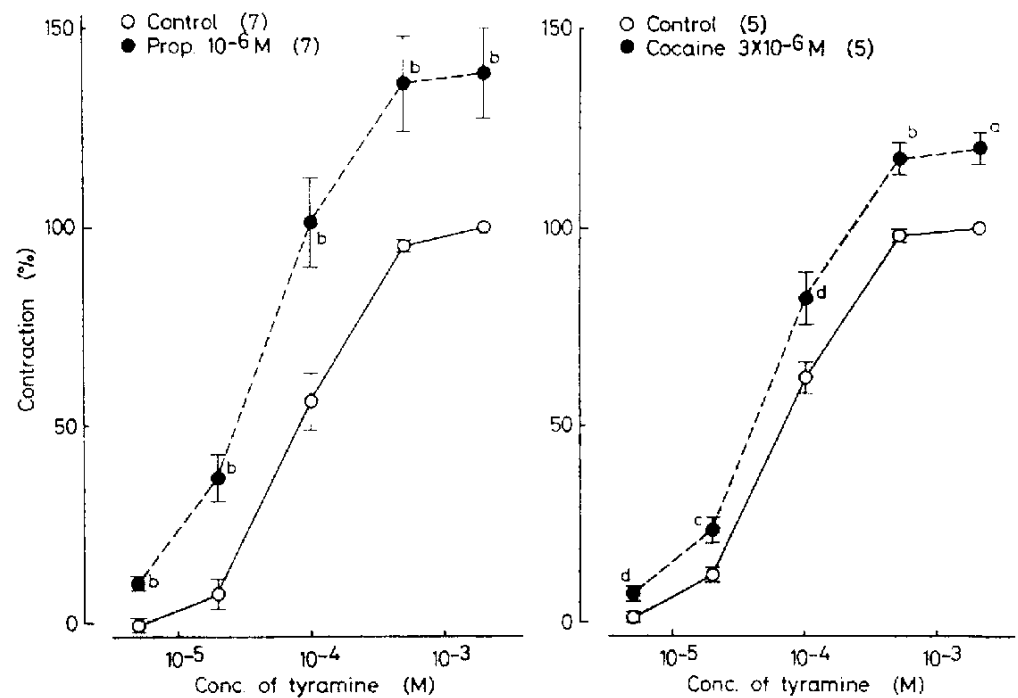

Fig. 4. Mudification of the contractile response to tyramine by propranolol and cocaine. Maximum cuntractions induced by tyramine in the control solution were taken as $100 \%$. mean absoluto values for teft and right figures were $822 \pm 183 \mathrm{mg}(\mathrm{N}=7)$ and $867 \pm 252 \mathrm{mg}$ $(N=5)$, respectively. a. significantly different from controls. $P=0.001 ; b, P \approx 0.01$ : c. P. $0.02 ; \mathrm{d}, \mathrm{P}, 0.05$
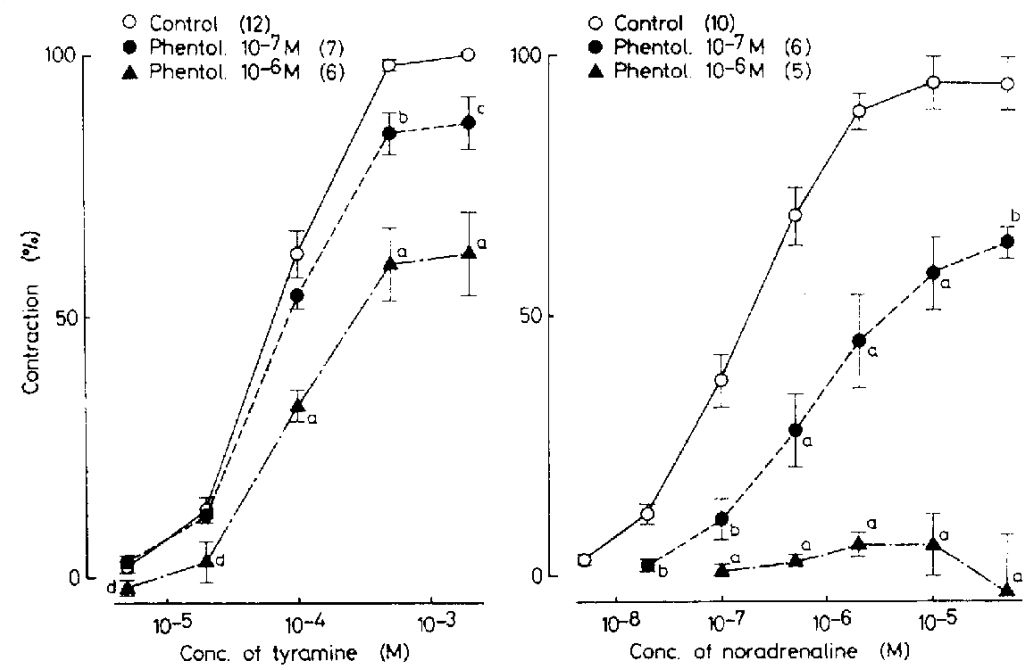

Fig. 5. Modification by phentolamine of contractile responses to tyramine and norepinepr:rine in the right figure, all preparations were treated with propranolol $\left(10^{-6} \mathrm{M}\right)$. Maximum contractions induced by tyramine (left) and norepinephrine (right) in the control solution were taken as 100\%; mean absolute values for left and right figures were $581 \pm 108 \mathrm{~m}$ $(N=12)$ and $1508 \pm 257 \mathrm{mg}(N=10)$. respectively. a, significantly different from controls. $P<0.001 ;$ b. P $=0.01 ;$ c. P $\cdots 0.02 ;$ d. P : 0.05 
phylaxis of the relaxation developed by repeated trials of tyramine, and the relaxation was abolished by cocaine, bretylium, sotalol. and propranolol. Norepinephrine in cencentrations up to $10^{-5} \mathrm{M}$ produced a marked relaxation of coronary arteries. These findings suggest that norepinephrine liberated from adrenergic nerves innervating the coronary arterial wall stimulates beta-adrenoceptors, resulting in relaxations. In our previous report using metoprolol, a selective beta, adrenoceptor antagonist, the beta-adrenoceptors in dog coronary artery are postulated to be beta ${ }_{1}$ (15).

In contrast to the present findings, responses of the coronary vascular bed to sympathetic nerve stimulation in vivo are indirect vasodilatation associated with increased myocardial metabolism (16) and direct vasoconstriction mediated by the stimulation of vascular alpha-adrenoceptors (17-21). In most of these in vivo reports, however, such a vasoconstriction irduced by the stimulation was obtained after the treatment with practolol or propranolol in order to eliminate the myocardial factor. In isolated coronary arteries, tyramine in a low concentration of $5 \times 10^{-6} \mathrm{M}$ also produced contractions, possibly via the release of norepinephrine in the presence of betablockade with sotalol, since the contractions were inhibited by cocaine and phentolamine. However, it is unlikely that the contractile response to tyramine of coronary arteries isolated from reserpine-pretreated dogs is mediated by liberated norepinephrine because of a marked depletion of endogenous norepinephrine (approx. 97\%, unoublished data) by the pretreatment with reserpine.

The release of norepinephrine as a mechanism of contractions induced by high concentrations $\left(2 \times 10^{-5} \mathrm{M}\right.$ or higher $)$ of tyramine may be excluded since treatment with reserpine in vivo or with cocaine in vitro dia not reduce the contraction. Potentiation of the contraction induced by cocaine and propranolol seems to be associated with an inhibition of relaxations. This inhibition by these antagonists seems to be induced by an interference with the neuronal uptake of tyramine and by a beta-adrenoceptor blockade, respectively. Phentolamine attenuated contractions induced by high concentrations $\left(2 \times 10^{-5} \mathrm{M}\right.$ or higher) of tyramine Norepinephrine-induced contractions which were unmasked by treatment with beta antagonists were also attenuated by phentolamine. These findings may indicate that high concentrations of tyramine contract coronary arterial strips due to a direct stimulatory action on alpha-adrenoceptors. However, non-specific vasoconstrictor actions may also be involved. since coronary arterial contractions induced by high concentrations of tyramine in the presence of betablockade were refractory to phentolamine at high concentrations which were sufficient to suppress the response to norepinephrine. Non-specific stimulatory action of tyramine is postulated in isolated intestinal preparations (22). Because treatment with cinanserin. chlorpheniramine. or aspirin fatied to alter the tyramine-induced contraction. the involvement of serotonergic, histaminergic $\mathrm{H}_{1}$, or prostaglandin-related mechanisms may be excluded.

\section{REFERENCES}

1) Burn, J.H. and Rand, M.J.: The action of sympathomimetic amines in animals treated with reserpine. J. Physiol. 144, 314-336 (1958)

2) de la Lande, I.S. and Waterson, J.G.: A comparison of the phamacology of the isolated rabbit ear and its central artery. Aust. J. exp. Biol. med. Sci. 46, 739-745 (1968)

3) Toda, N., Hayashi, S. and Hattori, K.: Analysis of the effect of tyramine and norepinephrine in isolated canine cerebral and mesenteric arteries. J. Pharmacol. exp. Ther. 205, 382-391 (1978)

4) Pegram, B.L., Bevan, R.D. and Bevan, J.A.: Facial vein of the rabbit neurogenic vasodiation mediated by $\beta$-adrenergic receptors. Circulation Res. 39, 854-860 (1976) 
5) Brine, F., Cornish, E.J. and Miller, R.C.: Effects of uptake inhibitors on responses of sheep coronary arteries to catecholamines and sympathetic nerve stimulation. Brit. J. Pharmacol. 67, 553-561 (1979)

6) Zuberbuhler, R.C. and Bohr, D.F.: Responses of coronary smooth muscle to catecholamines. Circulation Res. 16, 431-440 (1965)

7) Andersson, R., Holmberg. S., Svedmyr, N. and Ảberg, G.: Adrenergic $\alpha$ - and $\beta$-receptors in coronary vessels in man. An in vitro study. Acta med. scand. 191, 241-244 (1972)

8) Bohr, D.F.: Adrenergic receptors in coronary arteries. Ann. N. Y. Acad. Sci. 139, 799-807 (1967)

9) Morishita, H.: Distribution and characterization of the adrenoceptors in dog coronary arteries. Archs int. Pharmacodyn. Thér. 239, 195-207 (1979)

10) Dahlström, A., Fuxe, K., Mya-Tu, M. and Zetterström, B.E.M.: Observations on adrenergic innervation of dog heart. Am. J. Physiol. 209, 689-692 (1965)

11) Denn, M.J. and Stone, H.L.: Autonomic innervation of dog coronary arteries. J. appl. Physiol. 41, 30-35 (1976)

12) Hayashi, S., Miyazaki, M. and Toda, N.: Responsiveness to vasoactive agents of cerebral and mesenteric arteries isolated from control and reserpine-treated dogs. Brit. J. Pharmacol. $68,473-478$ (1980)

13) Toda, N., Hatano, Y. and Hayashi, S.: Modifications by stretches of the mechanical response of isolated cerebral and extracerebral arteries to vasoactive agents. Pflügers Arch.
$374,73-77(1978)$

14) Toda, N.: The action of vasodilating drugs on isolated basilar, coronary and mesenteric arteries of the dog. J. Pharmacol. exp. Ther. 191, 139-146 (1974)

15) Toda, N., Hayashi, S., Hatano, Y., Okunishi, $H$. and Miyazaki, M.: Selectivity and steric effects of metoprolol isomers on isolated rabbit atria, arteries and tracheal muscle. J. Pharmacol exp. Ther. 207, 311-319 (1978)

16) Berne, R.M.: Regulation of coronary blood flow. Physiol. Rev. 44, 1-29 (1964)

17) Feigl, E.O.: Sympathetic control of coronary circulation. Circulation Res. 20, 262-271 (1967)

18) Gerova, M., Barta, E. and Gero, J.: Sympathetic control of major coronary artery diameter in the dog. Circulation Res. 44, 459-467 (1979)

19) Kelley, K.O. and Feigl, E.O.: Segmental $\alpha$ receptor-mediated vasoconstriction in the canine coronary circulation. Circulation Res. 43, 908-917 (1978)

20) Malindzak, G.S., Jr., Kosinski, E.J., Green, H.D. and Yarborough, G.W.: The effects of adrenergic stimulation on conductive and resistive segments of the coronary vascular bed. J. Pharmacol, exp. Ther. 206, 248-258 (1978)

21) McRaven, D.R., Mark, A.L., Abboud, F.M. and Mayer, H.E.: Responses of coronary vessels to adrenergic stimuli. J. clin. Invest. 50, 773-778 (1971)

22) Jamieson, D.D. and Taylor, K.M.: Non-specific stimulant activity of tyramine on isolated intestinal preparations. Agents Actions 9, 422-427 (1979) 